\title{
59 PRODUCT CENTRIC INTEGRATION: EXPLORING THE IMPACT OF RFID AND AGENT TECHNOLOGY ON SUPPLY CHAIN MANAGEMENT
}

\author{
Jan Holmström* and Kary Främling \\ Industrial Engineering and Management \\ Helsinki University of Technology \\ POB 5500, FI-02015 HUT, FINLAND \\ *Corresponding author: jan,holmstrom@hut.fi
}

\begin{abstract}
The paper describes innovation action research on discovering RFID and agent applications that enable a move to simpler integrating mechanisms in the supply chain. The potential solution designs uncovered in the study simplify the information chain and reduce the need for management interventions in the organization and operation of customized delivery of products and services. The paper also illustrates how the adoption of novel technological tools does not automatically translate to performance improvements but requires stepwise exploration to develop and introduce the novel technologies in practice.
\end{abstract}

\section{INTRODUCTION}

Recently, automatic identification (such as RFID) and Internet applications have started to change the premises that underpin how inventory is managed in business firms. Real-time tracking over the Internet can be used to keep track of inventory in locations managed by other firms (Kärkkäinen et al., 2005). In a specific location the control and the ownership of materials may be in the hands of a number of different firms, each running their own inventory management solutions. The most obvious example is Vendor Managed Inventory where several suppliers may share the responsibility for inventory control in the warehouse of a distributor (see e.g. Holmström, 1998).

The implication on supply chain management (SCM) theory of real-time tracking and distributed responsibility is the need to revise the view that managing flows is the core of SCM. Currently SCM is widely defined as the management of material and information flows between actors linked to locations (Lummus and Vokurka, 1999; Mentzer et al, 2001). Real-time tracking is the basis for developing innovative supply chain solutions that are different from the flow oriented solutions that we have become used to, and even take for granted. Instead of monitoring and controlling material movements and the flows of material and information between predefined locations, supply chain management may also be conceived as customizing the movement of product and control information, individual shipments, end-products, and composite parts in a network of service providers ( see e.g. Kärkkäinen et al,, 2003; Främling et al., 2005).

This paper reports on an innovation action research study (Kaplan, 1998) that explores the consequences of RFID and real-time tracking on supply chain 
management practice and theory and which resulted in the above reconceptualization of supply chain management. The research contributes to the theoretical understanding of supply chain management, inter-organizational information systems, and extended enterprises, all of which are topics that Handfield and Melnyk (1998) considered to be in the early theory building stage, and in need of explorative and descriptive research. The research also attempts to relate a mature theory, inventory theory (Silver et al., 1998), to supply chain management and interorganizational information systems in a novel way.

\section{METHODOLOGY OF INNOVATION ACTION RESEARCH}

This paper explores the significance of tracking and RFID on SCM theory. The concepts and solution designs underpinning the theoretical analysis have been actively developed since the beginning of the year 2000. The goal of the research was in the beginning to evaluate and understand the theoretical impact of RFID on SCM, and was later refocused on tracking.

The research reported in this paper uses the innovation action approach (Kaplan, 1998). In an innovation action study the emergent relationship between phenomena, models, and theory has to be described. This is necessary because we are dealing with emergent phenomena. First there may be nothing, then there is just an idea, and in the end there are a multitude of phenomena, models, and explaining theory. The entities are treated as independent artefacts, that each can be improved and developed based on observed problems and improvements in the other entities.

The emergent nature of innovation action research is described in figure 1. The first idea of a novel solution leads through implementation of the design to the creation of new artificial phenomena. These phenomena are both intended and unintended consequences of the design (Popper, 1963, p. 461).

a)

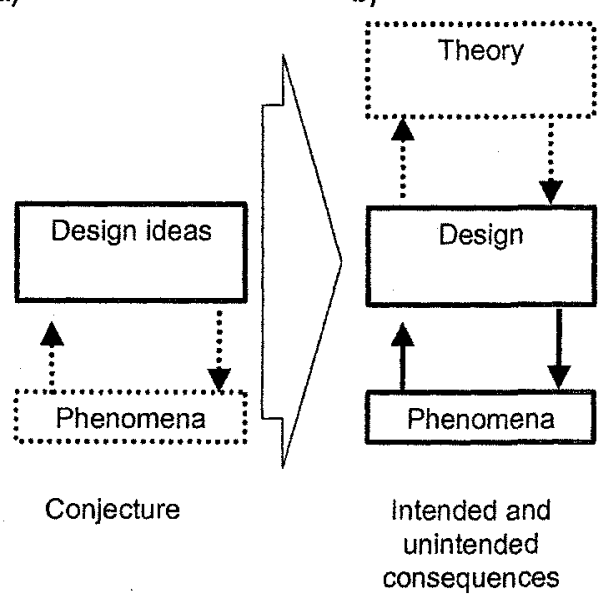

c)

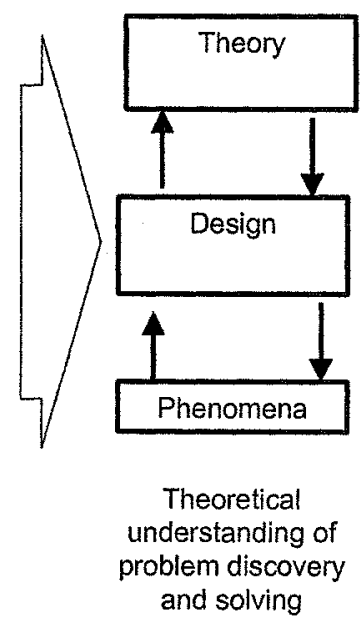

Figure 1 - Innovation action research studies phenomena that may not yet exist

The intended consequences are fulfilled design goals while the unintended often are new problems that need to be resolved. The last step is a theoretical understanding 
of the emergent phenomena, how they were created, and how to proceed in theory building as well as practical problem solving. This epistemology is consistent with McKelvey's semantic conception (2002), Popper's objective knowledge (1972), and Newell's knowledge levels (1981). It is also consistent with Handfield and Melnyk's (1998) description of theory building in operations management progressing from description and discovery to relationship building and theory refinement.

The first step in an innovation action study is difficult to describe and report. In order to make the base case development more transparent technical norms (Niiniluoto, 1993) are used in this paper. The technical norm is a statement describing what should or should not be done in a situation to achieve some specific goal, i.e. "If you want $A$, and you believe that you are in a situation $B$, then you ought to do X.". Account based inventory management that was discussed in the introduction can also be described as a technical norm. For example, it is the solution that should used to improve the accountability of material movements in situations where the material is kept in locations that can be clearly defined in advance and where responsibilities can be assigned per location.

\section{THE CASE EXAMPLE: EXPLORING PRODUCT TRACKING WITH RFID AND SOFTWARE AGENTS}

The case concerns the use of RFID and agent technology in logistics. The case is described by using a structure of three main-levels of analysis, with their respective sub-levels, these are:

- RFID and agent technology in logistics management (i.e. phenomena-level in figure 1)

- Problem discovery and solution design (i.e. design-level in figure 1)

- Evaluation and theoretical research (i.e. theory-level in figure 1)

\subsection{RFID and agent technology in logistics management}

RFID, or radio frequency identification, is a technology that makes it possible to identify physical objects by radio signal. There are two basic types of RFID tags, depending on how the tags transmit the identification information. In passive RFID a reading device activates by induction a radio circuit on the tag that is attached to the object. The activated tag then sends out a signal containing information about the object. In active RFID a transmitter that is attached to the object sends out the identification signal. The advantage with passive RFID is that the tag does not need to have an internal source of energy.

The identification of individual shipments and products is the major challenge that the application of RFID addresses in logistics. Any manual work involved in the identification and customized handling of shipments and individual products leads to a direct trade-off between efficiency and flexibility. In these situations reducing the manual work involved with identification and handling of individual products and parcels directly influences the performance frontier. In the parcel delivery industry companies such as UPS, DHL, and FedEx invest heavily in systems to identify and track parcels. Improvements in identification can be translated into improved handling efficiency and faster and better service. Partially due to better tracking and 
integrated information systems various expert couriers are able to deliver parcels within 24 hours in any place of the civilized world.

A software agent is an autonomous application in a distributed software architecture. Individual agent applications interact directly without centralized coordination. Such applications for logistics management have become feasible in practice with the arrival of the Internet. In logistics management software agents organized in peer-to-peer networks can potentially be used to establish secure, flexible and efficient communication of handling instructions and tracking information over the Internet.

Distributing handling and control information across a network of logistics service providers is the major challenge that agent technology addresses. In complex operational situations, such as production and project management, improvements in identification and peer-to-peer technology make it possible to develop innovative agent applications that reduce the need for management intervention. The performance frontier (Schmenner and Swink, 1998) is directly affected when these applications distribute control information more efficiently, reduce the need for manual integration, and make it easier to customize products and shipments.

\subsection{Problem discovery and solution design}

When starting the research the focus was on the application of RFID. Agent technology was not yet in the scope of interest. A focused review of industrial trials using RFID found that the potential impact on supply chain management, in addition to more efficient handling, and better integration of customization processes, is that it provides a new mechanism for information sharing and communication (Kärkkäinen and Holmström, 2002). This last point developed into a novel idea that would guide further research efforts by the research team. Product identification in combination with order information linked to the physical product was conceptualized as a tool for communicating important logistics and supply chain management information between companies. The term adopted to describe the idea was product centric supply chain management.

This conceptualization of product centric integration was on its own not a sufficient base case for starting work with industry. To find industrial partners interested to develop the concept a specific and relevant base case was needed. An interesting problem domain where product individuals already were controlled and monitored manually was found in the delivery of expensive equipment to project sites, for example the construction of new industrial plants.

In formulating the new base case the need to track the product individuals across many organisations surfaced and this prompted the researchers' interest in software agents and peer-to-peer systems. Identification and attaching instructions to the product individual was not sufficient in a project delivery environment. The location and movements of the product also needed to be recorded and monitored by project managers. To address this requirement the idea of linking a software agent to the individual product was introduced. It was proposed that the network of actors involved in the product delivery should access and update tracking and control information by referring to the product specific agent. This way a project manager, 
or other interested party, could follow the progress of a shipment at anytime over the Internet.

In the delivery of a project the project can be represented as an assembly of different services needed by a product individual. This product centric view of project delivery became the basis for formulating a concise base case in the form of a technical norm. Instead of looking at project delivery as a supply chain management problem, the goal for solution design was: "How can automated product identification and product specific software agents be used to improve the handling, customisation and other services needed by product individuals?" The answer is a technical norm (Niiniluoto, 1993) describing how a distributed information system (solution $X$ ) can be used to provide the logistics information management services (goal $\mathrm{A}$ ) needed in project delivery and similar temporary supply networks (situation B).

A paper describing the base case (Kärkkäinen et al., 2003) was completed at the same time as a consortium of industrial companies in the project delivery business was searching for ways to implement material visibility and control in project networks. The product centric concept was this way introduced to the research plan of the industrial consortium. A simple product centric track and trace system was implemented and field tested for large project deliveries. After the first test was finished an open source community was established for the further development of the solution, and to facilitate the adoption of the approach in other application areas (http://dialog.hut.fi). The Dialog Open Source is currently developed further in an EU funded research project within the 6th framework. The objective of the TraSer project is to bring product centric integration within the scope of progressive small and medium sized companies.

The approach was then tested in a company managing a large number of projects. The challenge for the second pilot company was managing expensive inventory in a large number of temporary storage locations. The original simple tracking and tracing functionality was enhanced in the pilot application with better data collection and monitoring features. The researchers could in the pilot see firsthand how product centric tracking could provide inventory monitoring functionality and creating inventory visibility in a changing network of companies.

The base case for product centric integration in project delivery was simplified and generalised based on the pilots and a number of feasibility studies with other industrial partners. The result was a mid-range theory on how to achieve inventory and material visibility in changing logistics networks. The mid-range theory describes a material and inventory visibility solution that focuses on the product individual or shipment. The advantage of this solution is that it is forwarder, or handler independent. This Forwarder Independent Tracking (FIT) approach and descriptions of feasibility analyses and successful pilots in short-term multicompany networks are described in Kärkkäinen et al. (2004).

\subsection{Evaluation and theoretical research}

Product centric integration across a changing network of participants has so far only been implemented in pilots. Despite the ability to more efficiently collect and distribute logistics management information finding interested industrial partners has been difficult. Even though the basic advantage is becoming clear, i.e. material 
visibility and improved integration of operations in changing environments, which together provide a basis for innovative and performance enhancing supply chain practices, companies have found it difficult to introduce product centric integration in their operations.

The pilot implementations imply that existing systems and the existing architecture of enterprise systems limit the adoption of product centric integration. The problem is that product centric integration, instead of linking locations and focusing on accountability and transactions between locations, focuses integration efforts on value added operations that individual products in the value-adding network require. Figure 2 is an attempt to illustrate the difference between a conventional transaction driven chain and a product centric supply chain. A conventional chain is based on a a systems design that is focused on location specific material accounts and transactions between locations. This design underpins the familiar supply chain representation that emphasizes the integration of locations and the integrated control of transaction processes. A solution design that tracks and controls individual products independently of the location and the ownership of the product individual underpins product centric integration. This fundamental difference in how the systems are designed and how integration is represented makes it challenging to combine product centric systems with current enterprise systems.

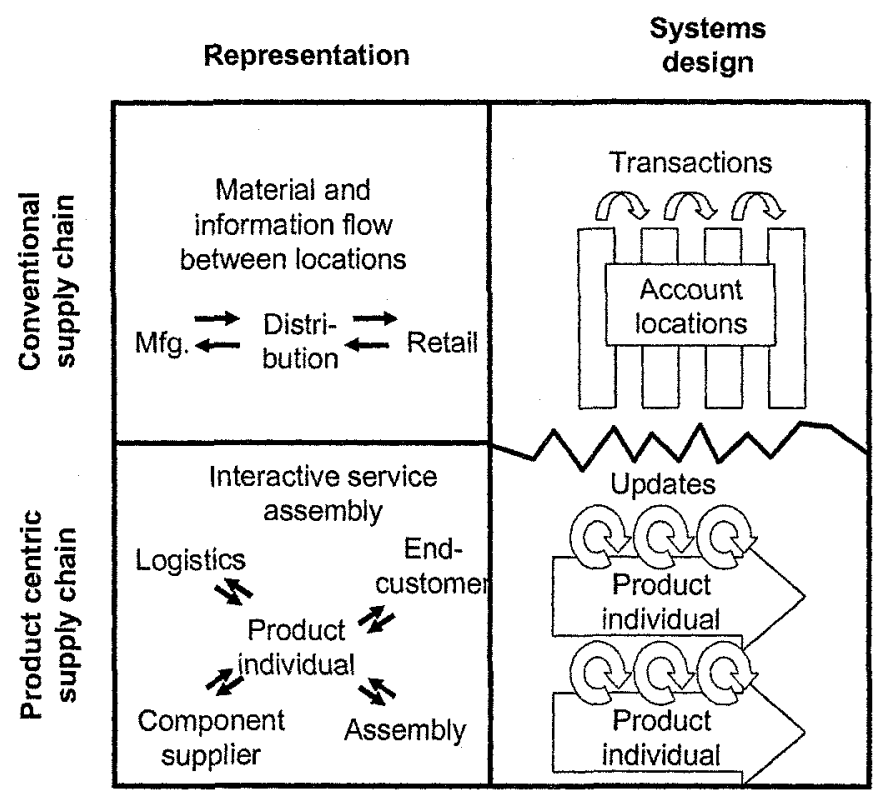

Figure 2 - centric and conventional supply chain management are underpinned by fundamentally different systems designs

The difference between material account and product individual focus requires further elaboration. The conventional supply chain is effective when well-defined standard goods are produced and can be delivered based on simple order and delivery transactions. For ordering and delivering more complex products advanced integrating mechanisms such as projects are needed. However, shifting to product centric integration makes explicit the role of the product as the co-ordinating entity 
in the delivery of customized products and many value added services (Callon et al, 2002). In a network of actors the recognition of the product as an integrating mechanism opens up opportunities to reduce the need for project management and a priori agreed handling and processing rules. In a product centric operation the service provider can refer to definitions linked to the product individual in many situations that before would have required human intervention and prior agreement. This way it is possible to move towards simpler integrating mechanisms and ad hoc integration (Galbraith, 1972).

Thus, the problem discovery and solution design described in the case can be understood as a finding a novel "virtual integration" mechanism and taking steps that potentially move the performance frontier for logistics operations in a changing environment.

\section{DISCUSSION}

Product centric integration across a changing network of participants has been implemented in two pilots. Despite a proven ability to more efficiently collect and distribute logistics management information finding industrial partners willing to invest in developing the pilots further is difficult. Even though the basic advantage is becoming clear, i.e. material visibility and improved integration of operations in changing environments, which together provide a basis for innovative and performance enhancing supply chain practices, companies find it difficult to introduce product centric integration in their operations.

The pilot implementations imply that existing systems and the existing architecture of enterprise systems limit the adoption of product centric integration. The problem is that product centric integration, instead of linking locations and focusing on accountability and transactions between locations, focuses integration efforts on the value added operations that individual products in the value-adding network require. A conventional chain is based on a systems design that is focused on location specific material accounts and transactions between locations. This design underpins the familiar supply chain representation that emphasizes the integration of locations and the integrated control of transaction processes. A solution design that tracks and controls individual products independently of the location and the ownership of the product individual underpins product centric integration. This fundamental difference in how the systems are designed and how integration is represented makes it challenging to combine product centric systems with current enterprise systems.

A fundamental theoretical benefit of the discovered alternative is that it is more loosely coupled (Gamma et al., 1995) to locations. Shifting to product centric solutions makes explicit the role of the product as the co-ordinating entity in a network of actors, and reduces the need for mutually agreed definitions of product states. It is a new alternative integrating mechanism that can be added to the list of already commonly used devices from the theory of organization design (Galbraith, 1972), and which links supply chain management to the economic theory of qualities (Callon et al., 2002).

Product centric integration should be considered in situations where the objective of the supply chain is project delivery, the value of items is high and have a complex lifecycle, or in general in situations where products and items require differentiated 
coordination. The implication of the research presented in this paper is that both operations managers and operations management scholars need to be aware of the product centric alternative, especially in demanding environments.

\section{ACKNOWLEDGEMENTS}

The authors wish to thank the Academy of Finland and TEKES (The Finnish Funding Agency for Technology and Innovation) for the grants that supported the explorative phase of our research and the European Commission for funding further development and exploitation in the TraSer project.

\section{REFERENCES}

1. Callon, M. , Méadel, C., and Rabeharisoa, V. ,2002. "The economy of qualities", Economy and Society, Vol 31, No 2, pp. 194-217.

2. Främling, K., Ala-Risku, T., Kärkkăinen, M., Holmström, J., 2005. "Design Patterns for Managing Product Lifecycle Information", forthcoming in Communications of the ACM

3. Galbraith, J. , 1972, Organization Design: An information processing view. In Jay W. Lorsch \& Paul R. Lawrence (Eds.), Organization planning: Cases and concepts. Homewood, Ill.: Irwin, 1972, pp. 49-72

4. Gamma, E., Helm, R., Johnson, R., Vlissides, J., 1995, "Design Patterns", Addison-Wesley Professional Computing Series, Reading, Massachusetts, USA, pp. 395.

5. Handfield, R., \& Melnyk, S., 1998. "The Scientific theory-building process: a primer using the case of TQM", Journal of Operations Management, 16(4), p. 321-339.

6. Holmström, J., 1998. "Business Process Innovation in the Supply Chain - A Case Study of Implementing Vendor Managed Inventory", European Journal of Purchasing and Supply Management, Vol. 4. No. 2/3, pp. 127-131

7. Kaplan, R. S., 1998. "Innovation Action research: Creating New Management Theory and Practice." Journal of Management Accounting Research, vol 10, pp.89-118

8. Karkkäinen, M, Holmström, J., 2002. "Wireless product identification: Enabler for handling efficiency, customisation, and information sharing." Supply Chain Management: An International Journal, vol. 7, no. 4, pp. 242-252

9. Kärkkäinen, M., Ala-Risku, T., Främling, K., 2003. "The product centric approach: a solution to supply network information management problems?" Computers in Industry, vol. 52, no. 2, pp. 147-159.

10. Kärkkäinen, M., Ala-Risku, T., and Främling, K., 2004. "Efficient tracking in short-term multicompany networks", International Journal of Physical Distribution \& Logistics Management, Vol. 34, No. 7., pp. $545-564$

11. Karkkainen, M., Ala-Risku, T., Främling, K., and Collin, J., 2005. "Establishing inventory transparency to temporary storage locations - A case from the mobile telecommunications industry", IFIP 5.7 Advances in Production Management Systems - conference (APMS 2005), Rockville, Maryland, the USA, September 19-21, 2005

12. Lummus, R. and Vokurka R., 1999. "Defining supply chain management: a historical perspective and practical guidelines", Industrial Management \& Data Systems, Vol. 99 Issue 1, pp 1-18

13. MeKelvey, B., 2002, Model-Centered Organization Science Epistemology. In J. Baum (Ed.), Companion to Organizations (pp. 752-780)

14. Mentzer, J., DeWitt, W., Keebler, J.; Soonhoong M.; Nix, N.; Smith, C., and Zacharia, Z., 2001. "Defining Supply Chain Management", Journal of Business Logistics, 2001, Vol. 22 Issue 2, pp 125.

15. Newell, A., 1982, "The knowledge level", Artificial Intelligence, vol. 18, pp. 87-127

16. Niiniluoto, I., 1993. "The Aim and Structure of Applied Research", Erkenntnis, Vol. 38, pp 1-21

17. Popper, K., 1963. "Conjectures and refutations - The Growth of Scientific Knowledge." First published by Routeldege \& Kegan Paul in 1963, Routeledge Classics edition 2002, London, UK

18. Popper, Karl, 1972. "Objective Knowledge - An Evolutionary Approach", Clarendon Press, Oxford, UK, Revised edition, 1979

19. Schmenner R. W. ja M. L. Swink, 1998. "On Theory in Operations Management", Journal of Operations Management, vol. 17 no. 1, pp. 97-113.

20. Silver, E., Pyke, D., and Peterson, R., 1998. "Inventory Management and Production Planning and Scheduling", John Wiley \& Sons, New York, 3rd edition. 